\title{
COVID-19 With an Initial Presentation of Intraperitoneal Hemorrhage Secondary to Spontaneous Splenic Rupture
}

\author{
Mohammed Knefati ${ }^{1}$, Ismail Ganim ${ }^{1}$, Jozef Schmidt ${ }^{1}$, Abhilash Makkar ${ }^{1}$, Stephanie Igtiben ${ }^{1}$, Eric Landa \\ ${ }^{1}$, Ahmad Tarawneh ${ }^{2}$, Courtney Hicks ${ }^{3}$, Stacy Zimmerman ${ }^{1}$, Suporn Sukpraprut-Braaten ${ }^{4}$ \\ 1. Internal Medicine, Unity Health, Searcy, USA 2. Pulmonary and Critical Care Medicine, Unity Health, Searcy, USA 3. \\ Infectious Diseases, Unity Health, Searcy, USA 4. Research, Unity Health, Searcy, USA
}

Corresponding author: Ismail Ganim, ismailganim@gmail.com

\begin{abstract}
The WHO declared coronavirus disease 2019 (COVID-19) a global pandemic in early 2020. As the pandemic has continued to evolve over a period of several months, many cases of unusual presentations are now emerging, which pose a greater challenge for physicians in terms of quickly identifying COVID-19 patients based on initial signs and symptoms. In this report, we present one such unusual presentation in a patient with sudden intraperitoneal hemorrhage and spontaneous splenic rupture with COVID-19 as the likely etiology and contributing factor.
\end{abstract}

The patient was a 75-year-old Caucasian woman who presented to the emergency department (ED) with complaints of severe left-sided abdominal pain for several days without any preceding trauma. A CT of the abdomen/pelvis revealed a large amount of fluid in the abdomen, which raised suspicion of bleeding. An exploratory laparotomy revealed splenic rupture with hemoperitoneum, and the patient subsequently underwent an emergent splenectomy. The patient's COVID-19 antigen test returned positive during the surgery and was subsequently confirmed with a polymerase chain reaction (PCR) test.

COVID-19 has been found to result primarily in respiratory symptoms through its ability to invade endothelial cells via angiotensin-converting enzyme 2 affinity. It is speculated that this mechanism may cause a predisposition to micro-thromboses, which can eventually lead to manifestations such as large lymphoid organ thrombosis. Based on this case presentation and the evolving literature on severe acute respiratory syndrome coronavirus 2 (SARS-CoV-2), spontaneous splenic rupture is an emergent differential diagnosis that should be considered in COVID-19 patients presenting with gastrointestinal complaints such as abdominal pain and nausea.

Review began 05/12/2021 Review ended 05/21/2021 Published 05/28/2021

() Copyright 2021 Knefati et al. This is an open access article distributed under the terms of the Creative Commons Attribution License CC-BY 4.0., which permits unrestricted use, distribution, and reproduction in any medium, provided the original author and source are credited.
Categories: Gastroenterology, Infectious Disease, Hematology

Keywords: intra-abdominal collection, covid-19, gastro-intestinal, atraumatic splenic rupture, hemato

\section{Introduction}

Severe acute respiratory syndrome coronavirus 2 (SARS-CoV-2) is the cause of the ongoing coronavirus disease 2019 (COVID-19) global pandemic. As of October 31, 2020, there have been more than 45.7 million cases of COVID-19 globally with more than 1.19 million deaths [1]. Although commonly manifested by fever (up to $90 \%$ of hospitalized patients) and respiratory symptoms (53-80\% of hospitalized patients) [2], the current estimates of asymptomatic infection range between $4-41 \%$ [3].

Many cases of unusual presentations of COVID-19 have also been reported, which poses a greater challenge for physicians as they may find it difficult to promptly identify patients of COVID-19 based on initial clinical signs and symptoms. One such presentation involves abdominal pain secondary to hemoperitoneum. Although splenic rupture is an emergency condition often secondary to trauma, here we present a patient with sudden intraperitoneal hemorrhage and spontaneous splenic rupture with COVID-19 as the likely etiology and contributing factor [4].

Splenic rupture is an acute emergency typically occurring due to trauma but can also occur in an atraumatic setting in rare cases. Atraumatic splenic rupture, which is routinely reported as spontaneous, has an approximate incidence rate of $0.1-0.5 \%[5,6]$. Typically, atraumatic etiologies include neoplastic diseases (30\%) and infectious (27\%), inflammatory (20\%), treatment-related (9\%), mechanical (7\%), and idiopathic causes [7].

Most notable among the infectious etiologies of spontaneous splenic rupture are infectious mononucleosis (40\%) and malaria (17\%) [7,8]; however, in recent years, reports of respiratory illness-associated splenic rupture have appeared in the literature. While cough-associated spontaneous splenic rupture has been discussed in the literature [7,9-11], pathologic splenic changes were noted during the 2003 SARS outbreak, 
which showed extensive damage to normal splenic architecture and altered immune cell numbers [12]. Analysis of spleens and immune cell distribution in patients with SARS-CoV-2 continues to reveal significant abnormalities in lymphocyte, granulocyte, and monocyte distributions [13]. Of note, exogenous administration of granulocyte colony-stimulating factor (G-CSF) has been associated with spontaneous splenic rupture [14]. Interestingly, G-CSF has been implicated in the pathogenesis of SARS-CoV-2 and identified as a driving factor of immune system dysregulation $[15,16]$. This marks one of the major differences between SARS-CoV-2-related splenic ruptures and other infectious and hematologic etiologies these result in splenomegaly in approximately $55 \%$ of cases [17]. Several case reports on spontaneous splenic rupture in patients with SARS-CoV-2 $[17,18]$ as well as splenic thromboembolic disease have surfaced within the last year [4,19-21]. We present a case of an elderly woman whose initial COVID-19 presentation at the hospital involved atraumatic/spontaneous splenic rupture in the absence of respiratory symptoms.

\section{Case Presentation}

A 75-year-old Caucasian woman with a past medical history of hypertension, hyperlipidemia, and atrial fibrillation with chronic anticoagulation on apixaban was brought to the emergency department (ED) due to severe abdominal pain. The patient had initially presented to her primary care physician (PCP) two days prior with nausea and emesis. The following day, she had developed left-sided abdominal and shoulder pain. She described the pain as constant, sharp, stabbing, and radiating diffusely across the abdomen. The pain, nausea, and vomiting had progressively worsened over the weekend, and hence she had decided to go to the hospital. She denied any fever, chills, cough, dyspnea, chest pain, or palpitations. She also denied any recent trauma. The patient did state that her husband had been having low-grade fevers at home.

The patient's vitals on physical examination were as follows: temperature (T) of $98.1^{\circ} \mathrm{F}$, blood pressure (BP) of $83 / 54 \mathrm{mmHg}$, a pulse rate of 86 beats per minute, respiratory rate (RR) of 18 breaths per minute, $\mathrm{O}_{2}$ saturation of $94 \%$ on room air, and pain rated as 10/10 in severity. She was in moderate pain and distress. Her heart sounds were regular and rhythmic, and peripheral perfusion was normal. Lungs were clear to auscultation without wheezing, rhonchi, or crackles. The abdomen was tender to palpation in the left upper and lower quadrants. Bowel sounds were hypoactive. There were no pulsatile masses, and the skin was without any rashes.

Her laboratory workup was significant for a positive COVID-19 antigen test, and her polymerase chain reaction (PCR) test was also positive. Her ferritin level was $317.9 \mathrm{mcg} / \mathrm{L}$; C-reactive protein (CRP) was $0.4 \mathrm{mg} / \mathrm{dl}$ at presentation but increased to $13.0 \mathrm{mg} / \mathrm{dl}$ within two days. Other lab findings were as follows: Ddimer of $0.81 \mathrm{mcg} / \mathrm{mL}$ FEU, WBC of $9.0 \times 1000 / \mathrm{mm}^{3}$, hemoglobin (HGB) of $12.3 \mathrm{~g} / \mathrm{dL}$, hematocrit (HCT) of $37.0 \%$, platelets (PLT) of $204 \times 1000 / \mathrm{mm}^{3}$, sodium (Na) of $138 \mathrm{MM} / \mathrm{L}$, potassium (K) of $3.6 \mathrm{MM} / \mathrm{L}$, chloride (Cl) level of $104 \mathrm{MM} / \mathrm{L}, \mathrm{CO}_{2}$ of $21 \mathrm{MM} / \mathrm{L}$, glucose (GLU) of $163 \mathrm{mg} / \mathrm{dl}$, blood urea nitrogen (BUN) of $23 \mathrm{mg} / \mathrm{dl}$, creatinine $(\mathrm{Cr})$ of $1.0 \mathrm{mg} / \mathrm{dl}$, haptoglobin of $179 \mathrm{mg} / \mathrm{dl}$, and procalcitonin of $0.32 \mathrm{ng} / \mathrm{mL}$.

A CT of the abdomen/pelvis obtained in the ED revealed a large subcapsular fluid collection measuring 3.2 $\mathrm{cm}$ in thickness, surrounding a small spleen and indicating a subcapsular hematoma (Figure 1). The spleen was noted to be small in size, measuring $7.8 \mathrm{~cm}$ longitudinally. The patient received IV Kcentra $3500 \mathrm{mg}$, IV Flagyl $500 \mathrm{mg}$, 2L lactated Ringer's (LR) bolus, IV morphine $4 \mathrm{mg}$, and IV Zofran $4 \mathrm{mg}$ while in the ED. 


\section{Cureus}

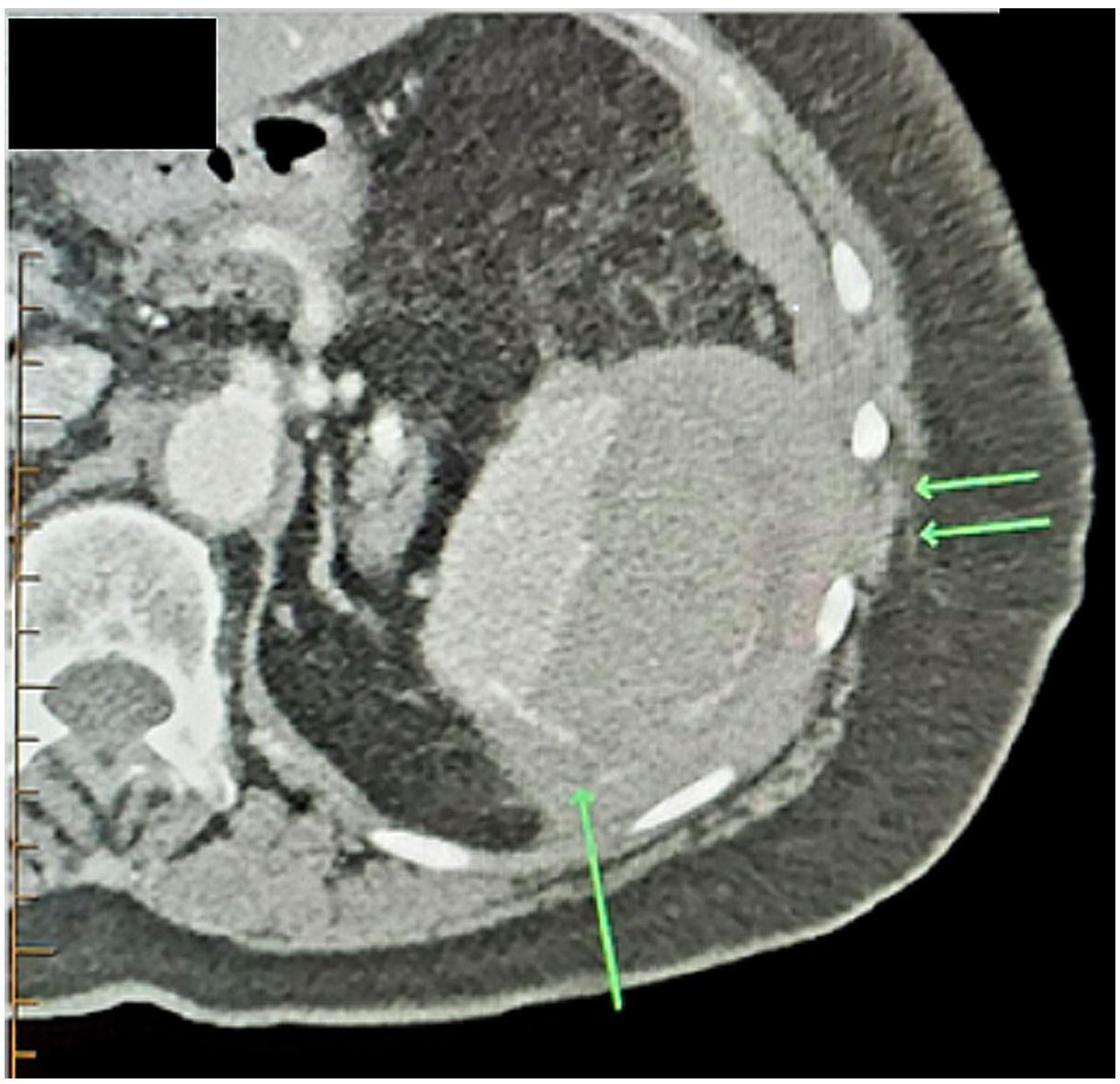

FIGURE 1: CT abdomen/pelvis of the patient's spleen

The image shows active extravasation (single arrow) and hematoma (double arrow)

CT: computed tomography

General Surgery was consulted, and the patient was taken to the operating room (OR) emergently for exploratory laparotomy. In the $\mathrm{OR}$, a ruptured spleen with hemoperitoneum was discovered and a splenectomy was successfully performed without complications. The patient's COVID-19 antigen test returned positive during the surgery and was subsequently confirmed with PCR. The patient's spleen was sent to the Pathology lab and, under microscopic analysis, an area of capsular rupture measuring $3.5 \times 1 \mathrm{~cm}$ was noted, with an associated area of subcapsular hemorrhage (Figure 2). 


\section{Cureus}

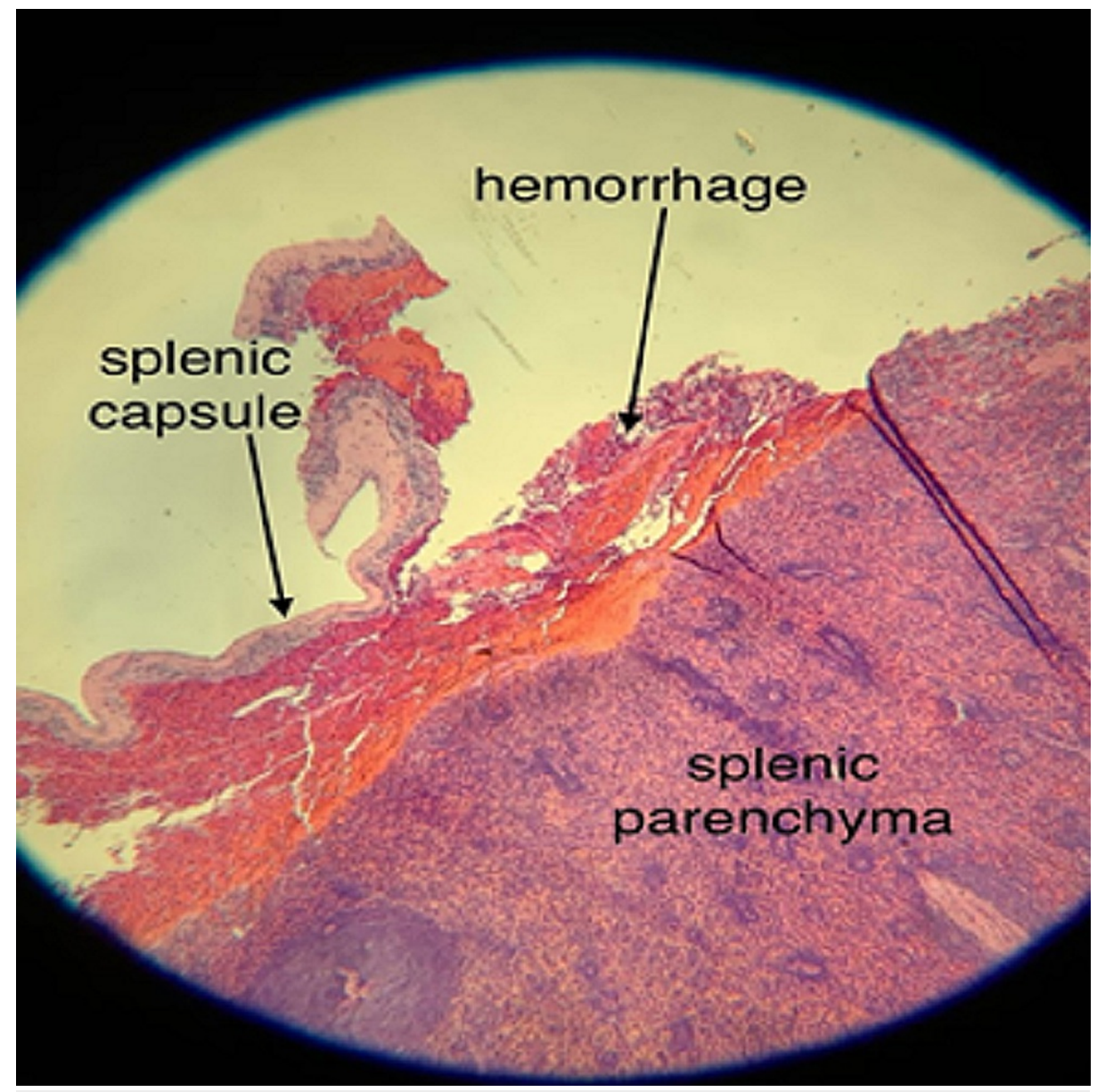

FIGURE 2: Microscopic image from Pathology lab revealing capsular rupture with an associated area of subcapsular hemorrhage

The patient's background information was unremarkable. She had not experienced any recent trauma; there was no significant family history, or any alcohol, tobacco, or illicit drug use. The only known risk factor the patient presented with was a positive COVID-19 test. The patient tolerated the surgery well and recovered without serious complications under ICU care.

\section{Discussion}

COVID-19 is associated with a wide range of symptoms including fever (70-90\% of hospitalized patients), dry cough (60-86\% of hospitalized patients), flu-like symptoms [22-29], and new loss of taste or smell (64$80 \%$ of all patients) [30-32].Interestingly, there have also been many reports associating COVID-19 with thrombotic diseases such as deep vein thrombosis, pulmonary embolism, stroke, and disseminated intravascular coagulation (DIC).

Although the mechanism is not fully understood, the condition is thought to cause respiratory symptoms by its ability to invade pulmonary endothelial cells through angiotensin-converting enzyme 2 affinity [22-25]. It is speculated that this endothelial dysfunction may cause a cascade of the activation of the inflammatory response, including components such as complement activation, leukocyte demargination, as well as activation of the immune response, which seems to lead to a predisposition to micro-thrombosis [26]. The degree of micro-thrombosis may impact the mortality rates of COVID-19 and is usually manifested subclinically without any acute intra-abdominal hemorrhagic indication [30,31].

In documented cases presenting with acute intra-abdominal manifestations such as spontaneous hemoperitoneum, patients are typically found to manifest respiratory symptoms or reveal labs significant for lymphopenia and elevated d-dimer levels, which represent inappropriate activation of coagulation leading to visceral infarction [32].

Interestingly, this COVID-19 patient presented without any respiratory symptoms and her coagulation parameters (negative D-dimer and normal platelet count) deviated from those seen in prior studies. Furthermore, on pathological examination, the patient's spleen measured $7.8 \mathrm{~cm}$ in length, which is smaller 
than the average size $(11.2 \mathrm{~cm})$ for women of this age range, and much smaller than what would be expected in viral infections typically associated with spontaneous splenic rupture, such as infectious mononucleosis and malaria, which often present with splenomegaly secondary to lymphocytic infiltration [33-37].

The precise etiology and mechanism for this patient's splenic rupture are still unclear. However, as similar cases continue to be reported in the literature, it is clear that presentations of abdominal pain in the setting of COVID-19 warrant further evaluation and that COVID-19 should be considered as another possible infectious cause of the spontaneous splenic rupture. Finally, there is currently much speculation regarding the physiological mechanism(s) by which COVID-19 may affect inflammatory and immune responses leading to coagulopathy and thromboses, and it is important to further investigate these issues as well given their clinical implications.

\section{Conclusions}

COVID-19 appears to physiologically manifest in a variety of multi-systemic phenomena, and clinicians must maintain a high degree of suspicion about the possibility of COVID-19 when evaluating patients with unusual symptoms, especially in relation to the possibility of micro-thromboses or primary lymphoid involvement. Based on this case presentation, spontaneous splenic rupture is an emergent differential diagnosis that should be considered in COVID-19 patients presenting with gastrointestinal complaints such as abdominal pain and nausea.

\section{Additional Information \\ Disclosures}

Human subjects: Consent was obtained or waived by all participants in this study. Conflicts of interest: In compliance with the ICMJE uniform disclosure form, all authors declare the following: Payment/services info: All authors have declared that no financial support was received from any organization for the submitted work. Financial relationships: All authors have declared that they have no financial relationships at present or within the previous three years with any organizations that might have an interest in the submitted work. Other relationships: All authors have declared that there are no other relationships or activities that could appear to have influenced the submitted work.

\section{References}

1. COVID-19 data in motion. (2020). Accessed: May 27, 2021: https://coronavirus.jhu.edu/.

2. Wiersinga WI, Rhodes A, Cheng AC, Peacock SI, Prescott HC: Pathophysiology, transmission, diagnosis, and treatment of coronavirus disease 2019 (COVID-19): a review. JAMA. 2020, 324:782-93. 10.1001/jama.2020.12839

3. Byambasuren O, Cardona M, Bell K, Clark J, McLaws M-L, Glasziou P: Estimating the extent of asymptomatic COVID-19 and its potential for community transmission: systematic review and metaanalysis [PREPRINT]. medRxiv. 2020, 10.3138/jammi-2020-0030

4. Karki S, Rawal SB, Malla S, Rayamajhi J, Thapa BB: A case report on spontaneous hemoperitoneum in COVID-19 patient. Int J Surg Case Rep. 2020, 75:211-3. 10.1016/j.ijscr.2020.09.078

5. Lai PK: Infectious mononucleosis: recognition and management. Hosp Pract. 1977, 12:47-52. 10.1080/21548331.1977.11707175

6. Kocael PC, Simsek O, Bilgin IA, Tutar O, Saribeyoglu K, Pekmezci S, Goksoy E: Characteristics of patients with spontaneous splenic rupture. Int Surg. 2014, 99:714-8. 10.9738/INTSURG-D-14-00143.1

7. Guy S, De Clercq S: Splenic rupture in community acquired pneumonia: a case report . Int J Surg Case Rep. 2016, 29:85-7. 10.1016/j.ijscr.2016.10.054

8. Won AC, Ethell A: Spontaneous splenic rupture resulted from infectious mononucleosis . Int J Surg Case Rep. 2012, 3:97-9. 10.1016/j.ijscr.2011.08.012

9. Toubia NT, Tawk MM, Potts RM, Kinasewitz GT: Cough and spontaneous rupture of a normal spleen . Chest. 2005, 128:1884-6. 10.1378/chest.128.3.1884

10. Wergowske GL, Carmody TJ: Splenic rupture from coughing. Arch Surg. 1983, 118:1227. 10.1001/archsurg.1983.01390100089024

11. Wehbe E, Raffi S, Osborne D: Spontaneous splenic rupture precipitated by cough: a case report and a review of the literature. Scand J Gastroenterol. 2008, 43:634-7. 10.1080/00365520701763472

12. Zhan J, Deng R, Tang J, et al.: The spleen as a target in severe acute respiratory syndrome . FASEB J. 2006, 20:2321-8. 10.1096/fj.06-6324com

13. Feng Z, Diao B, Wang R, et al.: The novel severe acute respiratory syndrome coronavirus 2 (SARS-CoV-2) directly decimates human spleens and lymph nodes [PREPRINT]. medRxiv. 2020, 10.1101/2020.03.27.20045427

14. Becker PS, Wagle M, Matous S, et al.: Spontaneous splenic rupture following administration of granulocyte colony-stimulating factor (G-CSF): occurrence in an allogeneic donor of peripheral blood stem cells. Biol Blood Marrow Transplant. 1997, 3:45-9.

15. Mehta P, Porter JC, Manson JJ, et al.: Therapeutic blockade of granulocyte macrophage colony-stimulating factor in COVID-19-associated hyperinflammation: challenges and opportunities. Lancet Respir Med. 2020, 8:822-30. 10.1016/S2213-2600(20)30267-8

16. Yang L, Liu S, Liu J, et al.: COVID-19: immunopathogenesis and Immunotherapeutics. Nature. 2020, 19:128.

17. Mobayen M, Yousefi S, Mousavi M, Shafighi Anbaran A: The presentation of spontaneous splenic rupture in a COVID-19 patient: a case report. BMC Surg. 2020, 20:220. 10.1186/s12893-020-00887-5 
18. Shaukat I, Khan R, Diwakar L, Kemp T, Bodasing N: Atraumatic splenic rupture due to covid-19 infection . Clin Infect Pract. 2021, 10:100042. 10.1016/j.clinpr.2020.100042

19. Qasim Agha O, Berryman R: Acute splenic artery thrombosis and infarction associated with COVID-19 disease. Case Rep Crit Care. 2020, 2020:8880143. 10.1155/2020/8880143

20. Wichmann D, Sperhake JP, Lütgehetmann M, et al.: Autopsy findings and venous thromboembolism in patients with COVID-19: a prospective cohort study. Ann Intern Med. 2020, 173:268-77. 10.7326/M20-2003

21. Santos Leite Pessoa M, Franco Costa Lima C, Farias Pimentel AC, Godeiro Costa JC, Bezerra Holanda JL: Multisystemic infarctions in COVID-19: focus on the spleen . Eur J Case Rep Intern Med. 2020, 7:001747. 10.12890/2020_001747

22. Li MY, Li L, Zhang Y, Wang XS: Expression of the SARS-CoV-2 cell receptor gene ACE2 in a wide variety of human tissues. Infect Dis Poverty. 2020, 9:45. 10.1186/s40249-020-00662-X

23. Tabary M, Khanmohammadi S, Araghi F, Dadkhahfar S, Tavangar SM: Pathologic features of COVID-19: a concise review. Pathol Res Pract. 2020, 216:153097. 10.1016/j.prp.2020.153097

24. Henry BM, de Oliveira MHS, Benoit S, Plebani M, Lippi G: Hematologic, biochemical and immune biomarker abnormalities associated with severe illness and mortality in coronavirus disease 2019 (COVID-19): a metaanalysis. Clin Chem Lab Med. 2020, 58:1021-8. 10.1515/cclm-2020-0369

25. García LF: Immune response, inflammation, and the clinical spectrum of COVID-19. Front Immunol. 2020, 11:1441. 10.3389/fimmu.2020.01441

26. McFadyen JD, Stevens H, Peter K: The emerging threat of (micro)thrombosis in COVID-19 and its therapeutic implications. Circ Res. 2020, 127:571-87. 10.1161/CIRCRESAHA.120.317447

27. Garg S, Kim L, Whitaker M, et al.: Hospitalization rates and characteristics of patients hospitalized with laboratory-confirmed coronavirus disease 2019 - COVID-NET, 14 states, March 1-30, 2020. (2020). Accessed: May 27, 2021: https://www.cdc.gov/mmwr/volumes/69/wr/mm6915e3.htm.

28. Guan WJ, Ni ZY, Hu Y, et al.: Clinical characteristics of coronavirus disease 2019 in China . N Engl J Med. 2020, 382:1708-20. 10.1056/NEJMoa2002032

29. Docherty AB, Harrison EM, Green CA, et al.: Features of 20133 UK patients in hospital with covid-19 using the ISARIC WHO Clinical Characterisation Protocol: prospective observational cohort study. BMJ. 2020, 369:m1985. 10.1136/bmj.m1985

30. Lechien JR, Chiesa-Estomba CM, De Siati DR, et al.: Olfactory and gustatory dysfunctions as a clinical presentation of mild-to-moderate forms of the coronavirus disease (COVID-19): a multicenter European study. Eur Arch Otorhinolaryngol. 2020, 277:2251-6. 10.1007/s00405-020-05965-1

31. Helms J, Kremer S, Merdji H, et al.: Neurologic features in severe SARS-CoV-2 infection . N Engl J Med. 2020, 382:2268-70. 10.1056/NEJMc2008597

32. Spinato G, Fabbris C, Polesel J, Cazzador D, Borsetto D, Hopkins C, Boscolo-Rizzo P: Alterations in smell or taste in mildly symptomatic outpatients with SARS-CoV-2 infection. JAMA. 2020, 323:2089-90. 10.1001/jama.2020.6771

33. Middeldorp S, Coppens M, van Haaps TF, et al.: Incidence of venous thromboembolism in hospitalized patients with COVID-19. J Thromb Haemost. 2020, 18:1995-2002. 10.1111/jth.14888

34. Levi M, Thachil J, Iba T, Levy JH: Coagulation abnormalities and thrombosis in patients with COVID-19. Lancet Haematol. 2020, 7 :e438-40. 10.1016/S2352-3026(20)30145-9

35. Tang N, Li D, Wang X, Sun Z: Abnormal coagulation parameters are associated with poor prognosis in patients with novel coronavirus pneumonia. J Thromb Haemost. 2020, 18:844-7. 10.1111/jth.14768

36. Oudkerk M, Büller HR, Kuijpers D, et al.: Diagnosis, prevention, and treatment of thromboembolic complications in COVID-19: report of the National Institute for Public Health of the Netherlands. Radiology. 2020, 297:E216-22. 10.1148/radiol.2020201629

37. Klok FA, Kruip MJHA, van der Meer NJM, et al.: Incidence of thrombotic complications in critically ill ICU patients with COVID-19. Thromb Res. 2020, 191:145-7. 10.1016/j.thromres.2020.04.013 